\title{
THE IMPORTANCE OF THE AEROSOL MONITORING IN RENEWABLE ENERGY
}

\author{
Calinoiu Delia-Gabriela $^{1^{*}}$, Trif-Tordai Gavrila ${ }^{2}$ And Ioana Ionel ${ }^{2}$ \\ ${ }^{1}$ Politehnica University Timisoara, Department of Fundamental of Physics for \\ Engineers, Timisoara, 300223, Romania. \\ ${ }^{2}$ Politehnica University Timisoara, Mechanical Engineering Faculty, \\ Timisoara, 300222, Romania. \\ *delia.calinoiu@upt.ro
}

\begin{abstract}
:
The study is relying on detailed physical and optical aerosol properties, data collected from the sun photometer located at Mechanical Engineering Faculty, Politehnica University Timisoara during 2016. Three days with moderate turbidity was selected by analyzing aerosol optical depth (AOD), Ångström parameter $(\alpha)$, Ångström turbidity coefficient $(\beta)$ single scattering albedo (SSA) and size distribution. A high AOD (>0.6), $\beta>0.1, \alpha>1.5$ and SSA decreases with the wavelengths which means that the atmosphere is loaded with biomass burning aerosol. Also, in this paper renewable energy production was analyzed during selected days with data taken from Transelectrica website, photovoltaic in particular.
\end{abstract}

Keywords: aerosol, climate change, renewable energy, photovoltaic

\section{Introduction}

Climate changes in the recent years [1] and the fear that fossil fuel reserves will be exhausted in the coming years prompted scientists to focus to alternative energy sources. A renewable energy source (RES), inexhaustible and free is obtained from the sun (using various conversion systems, e.g.: photovoltaic, thermal solar), wind, water and biomass. The European Union has set a binding target of $20 \%$ in final energy consumption from RES by 2020 , respectively $27 \%$ for 2030 [2]. The percentages of each EU country are shown in table 1 [2]. In 2016, $42.15 \%$ of Romanian electric energy consumption came from renewable sources, values taken from Transelectrica website [3], and represented in the figure 1 . The main RES's in Romania are hydro and wind power. Figure 1 shows that $3.47 \%$ (meaning 254.9 MW) from the total energy resulted from photovoltaics (PV). In Romania the annual solar energy flux is between $1000-1300$ $\mathrm{kWh} / \mathrm{m} 2 /$ year, with 210 sunny days per year [4]. This climate allows the operation of PV from March until October, with a conversion efficiency between $40 \%$ and $90 \%[5,6]$.
Energy production in Romania 2016

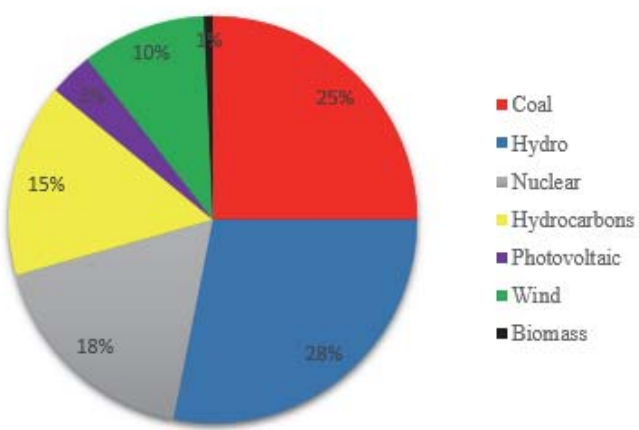

Figure 1. Energy production in Romania in 2016, according Transelectrica data [3]

The amount of the solar radiation falling on the surface depends the changing characteristics of the atmosphere [7]. For this reason, in recent years, besides solar radiation, the amount of aerosol in the atmosphere is also measured. The number of ground stations is still too small to achieve accurate global coverage. Alternatively, various models for estimating solar radiation are exploited in many applications. Choosing a model is often limited by the availability of the 
aerosol and meteorological parameters required for its running. In many cases the current values of the parameters are replaced with daily, monthly, yearly average values or even climatological reference values [8].

Table 1. Share of energy from RES in EU countries in 2005, 2015 and the target for 2020, in \% of gross final energy consumption [2].

\begin{tabular}{|l|l|l|l|}
\hline Country & 2005 & 2015 & 2020 \\
\hline Belgium & 1.9 & 7.9 & 13 \\
\hline Bulgaria & 9.4 & 18.2 & 16 \\
\hline Czech Republic & 6.1 & 15.1 & 13 \\
\hline Denmark & 17 & 30.8 & 30 \\
\hline Germany & 5.8 & 14.6 & 18 \\
\hline Estonia & 18 & 28.6 & 25 \\
\hline Ireland & 3.1 & 9.2 & 16 \\
\hline Greece & 6.9 & 15.4 & 18 \\
\hline Spain & 8.7 & 16.2 & 20 \\
\hline France & 10.3 & 15.2 & 23 \\
\hline Croatia & 23.5 & 29 & 20 \\
\hline Italy & 5.2 & 17.5 & 17 \\
\hline Cyprus & 2.9 & 9.4 & 13 \\
\hline Latvia & 32.6 & 37.6 & 40 \\
\hline Lithuania & 15 & 25.8 & 23 \\
\hline Luxembourg & 0.9 & 5 & 11 \\
\hline Hungary & 4.3 & 14.5 & 13 \\
\hline Malta & 0 & 5 & 10 \\
\hline Netherlands & 2.4 & 5.8 & 14 \\
\hline Austria & 23.3 & 33 & 34 \\
\hline Poland & 7.2 & 11.8 & 15 \\
\hline Portugal & 20.5 & 28 & 31 \\
\hline Romania & 17.8 & 24.8 & 24 \\
\hline Slovenia & 16 & 22 & 25 \\
\hline Slovakia & 6.7 & 12.9 & 14 \\
\hline Finland & 28.5 & 39.3 & 38 \\
\hline Sweden & 39.8 & 53.9 & 49 \\
\hline United Kingdom & 1.3 & 8.2 & 15 \\
\hline & & & \\
\hline
\end{tabular}

Atmospheric aerosol monitoring is done by remote sensing instruments (e.g. sun photometer) placed in ground stations, weather balloons, aircraft and satellites. Aerosol Robotic Network (AERONET) is a program founded in 1993 by NASA - GSPC (National Aeronautics and Space Administration - Goddard Space Flight Center) (http://aeronet.gsfc.nasa.gov/) and LOA - photons (Lille University, CNES Centre National D'études Spatiales and CNRS Le Centre National de la Recherche
Scientifique)

(http://www-loa.univ-

lille1.fr/photons/). This is a continuous database, accessible by the public, providing information on the aerosol optical and physical properties. The sun photometer from Timisoara has the position 645 in the AERONET grid.

\section{Experimental Data}

The experimental data was taken from sun photometer CE318, which is an automatic sun and sky radiometer, equipped with 9 spectral channels covering the spectral range 340 - 1640 $\mathrm{nm}$. The sun photometer is located on the roof of the Mechanical Engineering Faculty (Fig. 2), at Politehnica University Timisoara (45.74 N, $21.22 \mathrm{E}, 122 \mathrm{~m})$

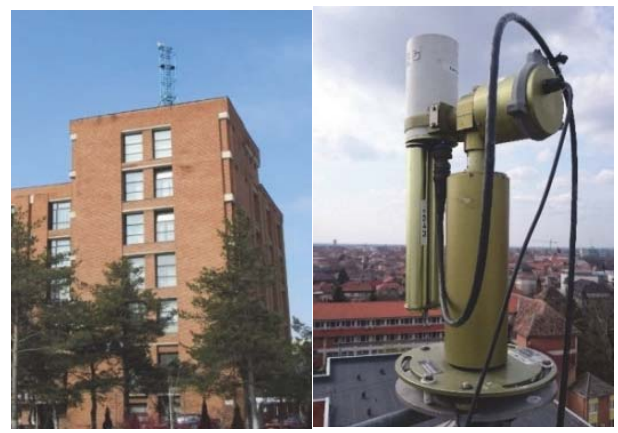

Figure 2. Sun photometer CE 318

The sun photometer accomplishes two basic measurements: (i) direct sun or (ii) sky measurement, both within several programmed sequences. The direct sun measurements are completed in nine spectral bands $(340,380,440$, 500, 670, 870, 940, 1020 and $1640 \mathrm{~nm}$ ), requiring approximately 10 seconds. The 940 $\mathrm{nm}$ channel is used for column water abundance determination [9]. This measurement are used to calculate the aerosol optical depth and the Ångström parameter.

Sky measurements are performed at $440 \mathrm{~nm}$, $670 \mathrm{~nm}, 870 \mathrm{~nm}$, and $1020 \mathrm{~nm}$. Two basic sky observation sequences are recorded: the "almucantar" and the "principal plane".

Solar radiation measurements in the "principal plan" are obtained by scanning the sky in a plane that contains the sun, the tool and the surface normal (optical head performs a moving from $6^{\circ}$ to $150^{\circ}$ ). Thus, in this case, the azimuth angle remains constant, and the scattering angles will vary, being carried out up to nine times a day. 
Size distribution and phase function is performed by obtaining the areola and diffuse radiation through a constant aerosol profile. These are determined by a large number of sun scattering angles. Thus, in "almuncantar" mode, over eight sequences of measurements are performed per day at atmospheric air mass of 4 , 3, 2 and 1.7 both morning and afternoon [9].

\section{Results and Discussion}

The aerosol parameters analyzed in this study are: a) Aerosol optical depth, values in the range of $0-2$ and is dimensionless ( 0 for an atmosphere without aerosol).

b) Ångström parameter $(\alpha)$ takes values between 0 and 2, and if value is: (i) $\alpha<1$ - denote large particles in the atmosphere - coarse particles (dust or marine aerosol), and (ii) $\alpha>1$ - denote small particles in the atmosphere - fine particles (urban - industrial pollution, aerosols originate from biomass burning).

c) Size distribution and effective radius.

d) Single scattering albedo (SSA) which takes values between 0 and 1 ( 1 is for scattering and 0 for a perfect absorber).

e) Ångström turbidity coefficient ( $\beta$ ) with values from 0 (clear atmosphere) to 0.5 (high aerosol load). In figure 3 , the AOD values are increasing during the day. The aerosols resulted from biomass burning are usually characterized by a single scattering albedo decreasing with wavelength, by high values of the Angström parameter (greater1.6), by high values of AOD (average is 0.409) and by an accumulation mode size distribution (the presence of fine particles). Average Ångström turbidity coefficient for August 6 is 0.11 , which confirm the presence of the aerosol in the atmosphere. For a good interpretation of the aerosol type, HYSPLIT (Hybrid Single - Particle Lagrangian Integrated Trajectory) model [10] and Global Fire Maps from MODIS (Moderate Resolution Imaging Spectroradiometer) are used [11].

In August 7 the average values of $\beta$ is 0.13 , AOD at wavelength $440 \mathrm{~nm}$ is 0.438 , the size distribution is bimodal and the fine mode predominates. By figure 4 it can observed that the amount of aerosol in atmosphere is increased. The amount of energy from PV is lower on August 7 compared to August 6.

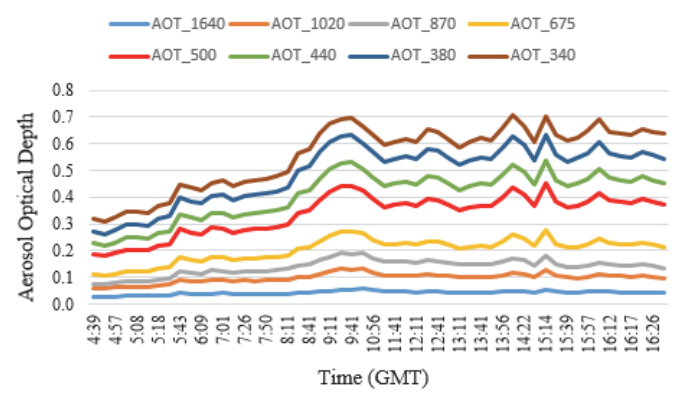

Figure 3. Aerosol optical Depth in Timisoara, 06.08.2016

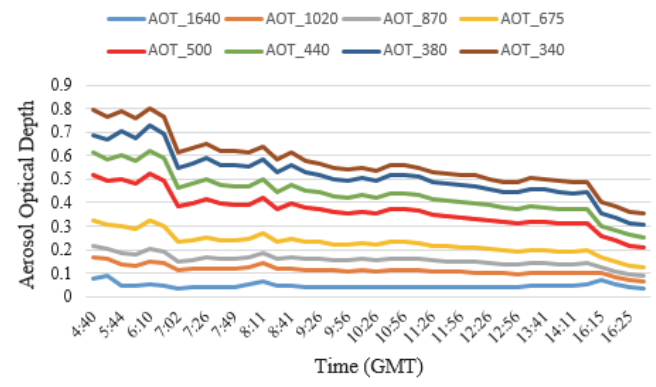

Figure 4. Aerosol optical Depth in Timisoara, 07.08.2016

The variation of the solar radiation is presented in figure 5. The amount of PV energy production in August 7 is $5.67 \%$ (362 MW), 6.13 (407 MW) in August 6, respectively 6.5\% (450 MW) in August 5.

As expected, in the summer the amount of energy from hydropower plants is smaller, respectively the energy from wind and photovoltaic plants is increased (fig.6), related to annual values (fig.1).

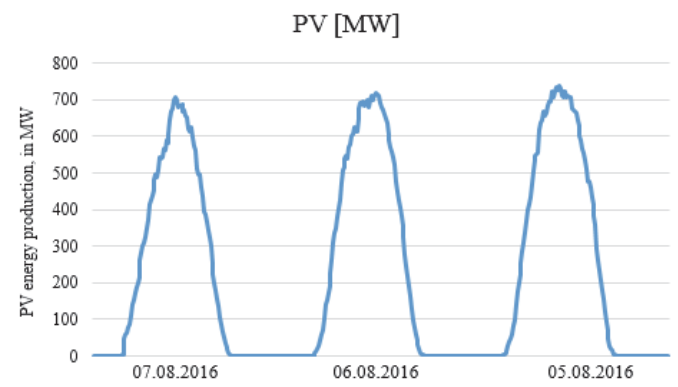

Figure 5. PV energy production, in 2016 August 05, 06 and 07 in Romania [3]. 


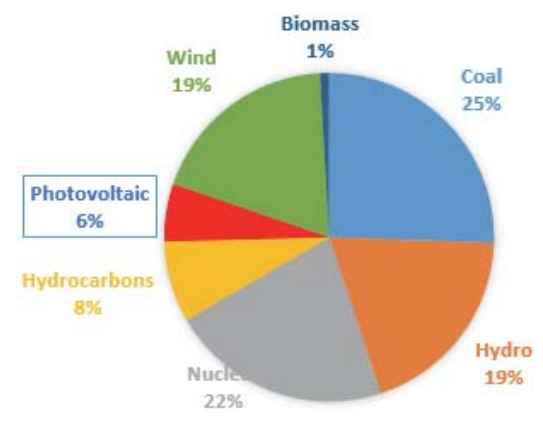

Figure 6. Energy production in Romania on August 7, 2016, according Transelectrica data [3]

Chosen episodes are not the most relevant since the values of $\beta$ are 0.11 and 0.13 , showing a decrease in PV efficiency.

Aerosols are one of the most variable components of the Earth's atmospheric, which influence the climate via two ways: the direct effect by scattering and absorbing incoming solar radiation and the indirect effect which modify the microphysical and hence the radiative properties, amount and lifetime of clouds. It is important to monitor the aerosol, because it has an impact on climate change and the environment, but also on our health.

Biomass burning aerosol have a significant impact on local and global climate (can absorb solar radiation in the atmosphere, producing the effect of cooling), regional air quality, visibility, cloud processes. In this case, the amount of solar radiation

\section{Conclusions}

The study was accomplished for 3 days from 2016 in Timisoara. The type of aerosol was determined by means of aerosol optical depth, single scattering albedo, Ångström parameter, Ångström turbidity coefficient and its dependence on wavelength, particle size distribution and effective radius. The origin of the air masses transporting the aerosols was investigated by running NOOA HYSPLITE model and by using Global Fire Maps from MODIS. From the analysis of the all aerosol parameters, concluded that the atmosphere is loaded with aerosol originating from biomass burning. In this case the amount of solar radiation reaching the surface of PV panels is smaller, and thus the efficiency is lower.

\section{Acknowledgment}

The research leading to these results has received funding from the European Union Horizon 2020 research and innovation programme under grant agreement No. 654109 and previously from the European Union Seventh Framework Programme (FP7/20072013), under grant agreement No 262254.

\section{References}

Intergovernmental Panel on Climate Change Climate Change (http://www.ipcc.ch/).

Share of renewables in energy consumption in the EU still on the rise to almost $17 \%$ in 2015 , Eurostat Newsrelease, 14 March 2017 (http://ec.europa.eu/eurostat) http://www.transelectrica.ro/web/tel/home European Bank for Reconstruction and Development (EBRD). Renewable Energy Resource Assessment. Romania. Country Profile; (2010).

C. Vac, S. Sana, F. Arion, Buletin UASVM Horticulture 68 (2011) 237.

S. E. Colesca, C. N. Ciocoiu, Renewable and Sustainable Energy Reviews 24 (2013) 149.

D. Calinoiu et al., Energy Conversion and Management 70 (2013) 76.

D. Calinoiu et al., Atmospheric Research 150 (2014) 69.

https://aeronet.gsfc.nasa.gov/ http://ready.arl.noaa.gov/HYSPLIT.php L.A. REMER, et al., Journal of the Atmospheric Sciences 62 (2005) 947 